\title{
Flood Frequency Analysis by Gumble Distribution for Krishnai River of Assam
}

\author{
Shonahar Ali ${ }^{1}$, Manash Pratim Kashyap ${ }^{2}$ \\ Research Scholar, Department of Statistics, Assam Downtown University, Guwahati, Assam, India ${ }^{1}$ \\ Assistant Professor, Department of Statistics, Assam Downtown University, Guwahati, Assam, India ${ }^{2}$
}

\begin{abstract}
This paper presents the study of annual maximum flood frequency analysis, by Gumble distribution at the Velterghat Gauging station for Krishnai river of Goalpara district of Assam. The chi-square test, Anderson Darling test is done to check the goodness of fit, which shows that the Gumble distribution fits the data. In addition Q-Q plot and P$\mathrm{P}$ plot are performed as a goodness of fit criteria.
\end{abstract}

Keywords: Frequency, Flood, Gumble, Distribution, Parameter

\section{INTRODUCTION}

Flood is part of nature which always to be existed. The natural disaster occurs not only in Assam, but in all part of world. It is the most costly natural hazard since its ability to destroy human lives and properties. So a preventive measure has to be taken to save unnecessary cost and economic loss as well as preventing danger due to over flow of water in Assam. This can be done by construction of barrages, dams, water reservoirs and widening or Deeping the river. These require high financial cost as well as high potential in destroying the ecosystems of the river itself. Thus these flood protection projects without proper planning and designing will only create drawbacks. So, to reduce the drawbacks, information related to these aspects need be carefully considered. A clear knowledge related to magnitudes and their frequencies of the flood occurrences are basically needed to overcome all that types of difficulties. Information regarding accurate estimation of flood magnitudes and their frequencies occurrence are of great importance in planning, designing and management of each structure at the location or station of interest. The design should be done by considering the maximum flows that exceeds certain level in a given return period. On the other hand, the flows below the critical value are less important since they do not negatively affect the design.

\section{METHODOLOGY}

The research methodology is as follows

A. Study Area: The river Brahmaputra basin is nearly an area of 580,000 $\mathrm{km}^{2}$ and lies in Tibet, Bhutan, India and Bangladesh. The drainage area of the basin lying in India is $194,413 \mathrm{~km}^{2}$; which form nearly $5.9 \%$ of the total geographical area of the country.

The main study area of the Krishnai river catchment is belongs to the states of Meghalaya and Assam. The physiographic of the entire region is mainly divided into two divisions, namely the Meghalaya plateau and the plains of river of river Brahmaputra valley which falls into the state of Assam accounting for about $70 \%$ and $30 \%$ of the total area respectively. The Assam state comprises of two main river valleys. The northern valley is called the Brahmaputra valley and the southern valley is known as Surama and Barak valley. The plain valley Brahmaputra lies between the foot hills of Bhutan range on the north and two other hill tracts of Naga,Mikir,Ksasiya , Jayantia,Garo hills etc on the south. The Brahmaputra valley is nearly is nearly $720 \mathrm{~km}$. long and $80 \mathrm{~km}$. wide covering about 56339 square km. of riverine area between both banks of the brahmuptra starting from Sodiya in the east and Dhubri in the west. The river Brahmuptra receives number of tributaries and sub-tributaries throughout its course.The river Dudhnoi is one of such major south bank tributary. The river Krishnai is again a tributary of the river Dudhnoi. The river Krishnai originates in Meghalaya from Garo hills at an elevation of about $280 \mathrm{~m}$ above mean sea level and meets with river Dudhnoi near Tomuni at about $12 \mathrm{~km}$ north from Dudhnoi at an elevation of about $150 \mathrm{~m}$ above mean sea level and finally flows towards river Brahmuptra. A good number of streams originating from Garo hills having elevation between 500m to $300 \mathrm{~m}$ above mean sea level fall to the Krishnai river in the Meghalaya area which produces good discharges for Krishnai river. The Krishnai river catchment lying between $25^{\circ} 35^{\prime}$ to $26^{\circ} 2^{\prime}$ north latitude and $90^{0} 20^{\prime}$ to $90^{\circ} 45^{\prime}$ east longitude is in Garo hills district of Meghalaya, in the northern slope of the state adjoining Assam. 


\title{
International Advanced Research Journal in Science, Engineering and Technology
}

\author{
Vol. 5, Issue 10, October 2018
}

B. Data: Annual peak discharge flow data (in $\mathrm{m}^{\wedge} 3 / \mathrm{s}$ ) covering 46 years of records i.e. from 1972 to 2018 for the Veltherghat Gausing station on Krishnai river were obtained from Goalpara Investigation Division (Irrigation), Goalpara.

C. Gumble Distribution: In hydrology the type I extreme value distribution is known as Gumble distribution. Gumble in 1941 was the first to consider the use of distribution of largest values as suggested by Fisher and Tippet. The Type-I extreme value distribution is also known as Double Exponential distribution. Gumble was the first to consider that the annual flood peaks are extreme value of flood in each of the annual series of recorded flood or rainfall. There are two methods of analyzing the flood peaks. They are the annual maximum series and the partial duration series. The annual numbers of observations are sufficiently large and are independent of each other and hence the highest peak discharge recorded every year is used for analysis. In partial duration series, all flood discharges above a threshold in any year are taken for analysis. In this study, the annual peak discharge series of 46 years of Krishnai river has been analyzed. To analyze the data Graphical plotting formula which optimize Gumble distribution is as given below

observation.

$$
\mathrm{qi}=\frac{i-a}{N+1-2 a} \text { and } \mathrm{pi}=1-\mathrm{qi} \text {; Where qi =exceedance probability associated with each }
$$

$$
\mathrm{N}=\text { Number of annual maximum observation. }
$$

$\mathrm{i}=$ Rank of specific observation with $\mathrm{i}=1$ being the largest to $\mathrm{i}=\mathrm{N}$ being the smallest observation.

$\mathrm{a}=$ constant for estimation= 0.44 using Gringoten's method.

Now to calculate the Return period of flood, let $\mathrm{X}$ is a random variable, which has a cumulative distribution function $F_{X}(X)$. The probability that $X$ is less than equal to a given event $\mathrm{Xp}$ is given by

$$
\mathrm{F}_{\mathrm{X}}(\mathrm{x})=\mathrm{P}(\mathrm{X} \leq \mathrm{Xp})=\mathrm{p}
$$

The probability that this event will be exceeded is then equal to 1-p and the percent exceedance is denoted as $100(1-p)$. For such an event $\mathrm{Xp}$, the return period corresponding to this exceedance probability is denoted by $\mathrm{T}$ where, $\mathrm{T}=\frac{1}{1-\mathrm{P}}$; Using this definition, the 100- year return period can be understood as an event with a probability of exceedance $=1$ $\mathrm{p}=0.01$ or a non-exeedance probability $\mathrm{p}=0.99$; ie there is a $99 \%$ chance that this event will not be exceeded within a given year. The Tp estimated represents the estimated distribution using $\mathrm{T}=\frac{1}{1-\mathrm{P}}$

Now we assume that the data follows Gumble distribution and so the parameter of this distribution is to be estimated. The CDF of the extreme value Type-I or Gumble distribution is given by

$$
\mathrm{F}_{\mathrm{X}}(\mathrm{x})=\operatorname{Exp}\left[-\exp \left(-\frac{x-u}{\alpha}\right)\right]=\mathrm{p} \text {; where } \mathrm{x} \text { is the observed discharge data } \mathrm{u} \text { and } \alpha \text { are the calculated parameters of }
$$

the distribution. In order to calculate the theoretical estimate of ' $\mathrm{P}$ ' the following formulas is used $\quad \frac{\sum_{i=1}^{n} x i}{n}=\frac{{ }_{i=1}}{n}$

$\mathrm{Sx}^{2}=\frac{1}{n-1} \sum_{i=1}^{n}(x-\bar{x})^{2}$

$u=\bar{x}-0.5772 \alpha$

$\alpha=\frac{\sqrt{6} s_{x}}{\pi}$

D. Quantile - Quantile (Q-Q) Plot And P-P Plot: If the data follow the assumed distribution, then the points on the Q-Q plot will fall approximately on a straight line. A Q-Q plot is a plot of the quantiles of the first data set against the quantiles of the second data set.

P-P plot A P-P plot compares the empirical cumulative distribution function of a data set with a specified theoretical cumulative distribution $\mathrm{F}($. 


\section{International Advanced Research Journal in Science, Engineering and Technology}

Vol. 5, Issue 10, October 2018

Table I.The Summary of calculation for exceedance probability is given as follows.

\begin{tabular}{|c|c|c|c|c|}
\hline Year & Data $\left(m^{\wedge} 3 / s\right)$ & Tp Estimated & p theoretical & Tp theoretical \\
\hline 2016 & 113.48 & 1.012291484 & 0.567921818 & 2.314395965 \\
\hline 2001 & 129.14 & 1.035008977 & 0.568062245 & 2.315148393 \\
\hline 2011 & 150.2 & 1.058769513 & 0.568251052 & 2.316160824 \\
\hline 2002 & 150.61 & 1.083646617 & 0.568254727 & 2.31618054 \\
\hline 1997 & 158.22 & 1.109720885 & 0.56832294 & 2.316546539 \\
\hline 2008 & 166.72 & 1.137080868 & 0.568399123 & 2.316955439 \\
\hline 2003 & 186.91 & 1.165824065 & 0.568580048 & 2.317927106 \\
\hline 1994 & 191.17 & 1.196058091 & 0.568618217 & 2.318132197 \\
\hline 2006 & 197.91 & 1.227902023 & 0.568678602 & 2.318456737 \\
\hline 2013 & 198.98 & 1.261487965 & 0.568688188 & 2.318508264 \\
\hline 1998 & 201.88 & 1.29696288 & 0.568714168 & 2.318647927 \\
\hline 1999 & 204.15 & 1.334490741 & 0.568734503 & 2.318757258 \\
\hline 2005 & 208.57 & 1.374255066 & 0.568774098 & 2.31897016 \\
\hline 1990 & 222.02 & 1.416461916 & 0.568894569 & 2.319618189 \\
\hline 2010 & 222.06 & 1.461343473 & 0.568894927 & 2.319620117 \\
\hline 2000 & 229.1 & 1.509162304 & 0.568957976 & 2.319959411 \\
\hline 2007 & 247.25 & 1.560216509 & 0.5691205 & 2.320834477 \\
\hline 2015 & 264.39 & 1.614845938 & 0.569273946 & 2.321661276 \\
\hline 1975 & 284.93 & 1.673439768 & 0.569457789 & 2.322652634 \\
\hline 2012 & 285.26 & 1.736445783 & 0.569460742 & 2.322668566 \\
\hline 1981 & 296.77 & 1.804381847 & 0.569563742 & 2.32322436 \\
\hline 1996 & 302.93 & 1.877850163 & 0.56961886 & 2.323521891 \\
\hline 1985 & 334.6 & 1.957555178 & 0.569902169 & 2.325052416 \\
\hline 1978 & 339.21 & 2.044326241 & 0.5699434 & 2.325275324 \\
\hline 1991 & 345.36 & 2.139146568 & 0.5699984 & 2.325572742 \\
\hline 1980 & 345.54 & 2.243190661 & 0.57000001 & 2.325581448 \\
\hline 1987 & 376.28 & 2.357873211 & 0.570274858 & 2.327068869 \\
\hline 1976 & 376.63 & 2.484913793 & 0.570277987 & 2.327085812 \\
\hline 2004 & 393.42 & 2.62642369 & 0.570428063 & 2.327898808 \\
\hline 1983 & 419.53 & 2.785024155 & 0.570661384 & 2.329163888 \\
\hline 2009 & 458.07 & 2.964010283 & 0.571005644 & 2.331033 \\
\hline 2017 & 464.33 & 3.167582418 & 0.571061547 & 2.331336797 \\
\hline 1972 & 519.1 & 3.401179941 & 0.571550464 & 2.333997161 \\
\hline 1982 & 553.8 & 3.671974522 & 0.571860052 & 2.335684873 \\
\hline 1988 & 559.82 & 3.989619377 & 0.571913748 & 2.335977844 \\
\hline 1979 & 567.98 & 4.367424242 & 0.571986526 & 2.336375044 \\
\hline 1984 & 596.43 & 4.824267782 & 0.572240209 & 2.337760632 \\
\hline 1977 & 610.6 & 5.387850467 & 0.572366527 & 2.33845118 \\
\hline 1986 & 622.54 & 6.100529101 & 0.572472948 & 2.339033276 \\
\hline 1992 & 641.81 & 7.030487805 & 0.572644669 & 2.339973152 \\
\hline 1974 & 646.19 & 8.294964029 & 0.572683695 & 2.340186857 \\
\hline 1993 & 697.51 & 10.11403509 & 0.5731408 & 2.342692858 \\
\hline 1989 & 724.2 & 12.95505618 & 0.573378411 & 2.343997648 \\
\hline 1995 & 833.6 & 18.015625 & 0.57435154 & 2.349356556 \\
\hline 1973 & 833.99 & 29.56410256 & 0.574355007 & 2.349375691 \\
\hline 2014 & 930.37 & 82.35714286 & 0.575211221 & 2.354111145 \\
\hline
\end{tabular}




\section{International Advanced Research Journal in Science, Engineering and Technology}

Vol. 5, Issue 10, October 2018

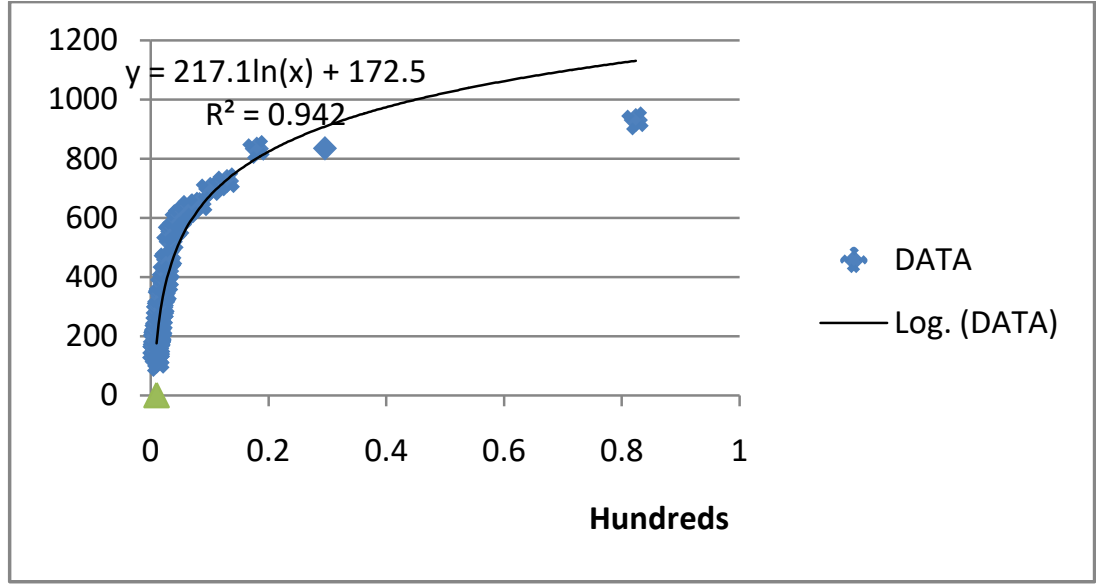

Fig.1 .Flood Frequency Curve by Gumble

\section{FITTING OF THE GUMBLE DISTRIBUTION BY MAXIMUM LIKELIHOOD(ML) METHOD}

In this section, parameters and test statistic as calculated as follows.

\section{A. Parameters}

Estimate

a 290.0530

b 157.6314

B. Loglikelihood: -307.0503

C. Correlation matrix:

a

$\begin{array}{lll}\text { a } & 1.0000000 & 0.3040407\end{array}$

b $\quad 0.3040407 \quad 1.0000000$

$$
\text { b }
$$

Std. Error

24.40236

19.30578

0503 AIC: 618.1005 BIC: 621.7578
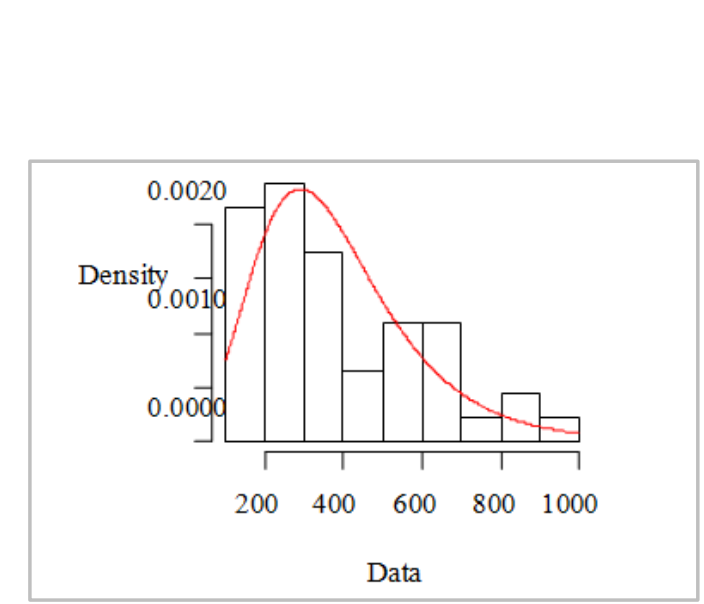

Figure 2. Empirical and Theoretical Density

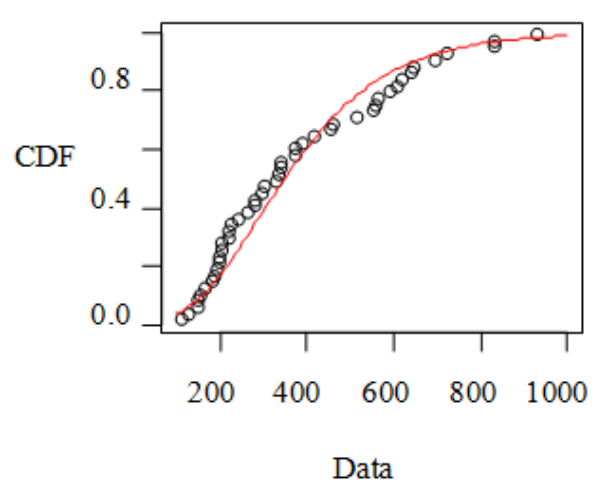

Figure 3. Empirical and Theoretical CDFs

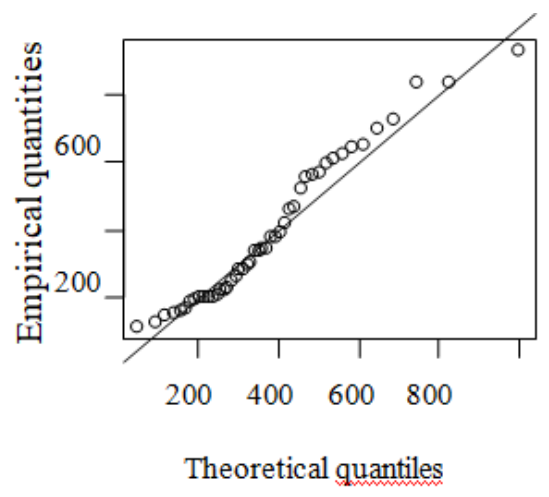

Figure 4. Q-Q plot 


\section{International Advanced Research Journal in Science, Engineering and Technology}

Vol. 5, Issue 10, October 2018

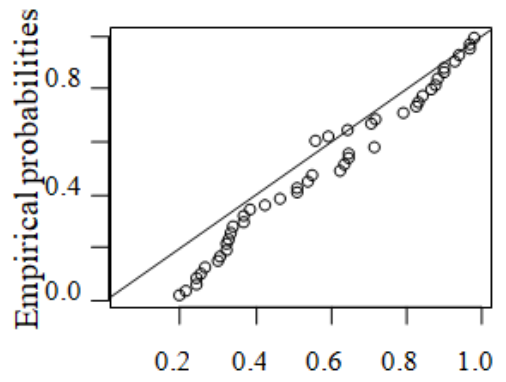

Theoretical probabilities

Figure 5. P-P plot

IV.

\section{RESULTS AND DISCUSSION}

From the Q-Q plot, P-P plot and Empirical and theoretical CDFs plots of the fitted distribution it is seen that all the plots are around the lines respectively indicating that the data is fitted for the assumed distribution. The KolmogorovSmirnov, Andrson-Darling and Chi-square test was applied to check the goodness of fit. The entire tests revealed a good fit as summarized in the following table.

Table 2.Shows the results of test statistic with sample size $=46$.

\begin{tabular}{|l|l|l|}
\hline Test name & Statistic & $\mathrm{p}$-value \\
\hline Kolmogorov-Smirnov test & 0.11194 & 0.57305 \\
\hline Anderson- Darling test & 0.72352 & - \\
\hline Chi-square test & 04.2743 & 0.37016 \\
\hline
\end{tabular}

\section{CONCLUSION}

This study provides the flood frequency analysis of annual maximum flows for 46 years of Krishnai river by Gumble distribution model. The result shows no significant differences between the predicted and observed flow magnitudes. Hence the model can be used to predict the maximum flood flows for the river.

\section{REFERENCES}

[1]. Adamowski, K.(2000) Regional analysis of maximum and partial duration flood data by nonparametric andL-moment method. Journal of Hydrology 229 (3-4):219-231,

[2]. Alila, Y. (1999) A hierarchical approach for the regionalization of precipitation annual maximum in Canada.J Geophys Res-Atmos 104 (D24):31645-31655.

[3]. Burn, D.H. (1997) Catchment similarity for regional flood frequency analysis using seasonality measures. Jornal of Hydrology 202 (1-4):212230.

[4]. Chow, V.T.(1964) Handbook of Applied Hydrology.Mc Graw Hill,New York.

[5]. Conway, D. (2000) The climate and hydrology of the Upper Blue Nile river. The Geographical Journal 166:49-62.doi:DOI 10.1111/j.14754959.2000.tb00006.x

[6]. Dalrymple, T. (1960) Flood frequency methods. U.S. Geological Survey Water Supply paper,1543A

[7]. Eregno, F.E. (2014) Regional Flood Frequency Analysis Using L-Moment in the Tributaries of Upper Blue Nile River, South Western Ethiopia. Merit Research 2(2) 012-021

[8]. Kumar R.,Borah M.,\&Bhuyan A.(2009) Regional Flood Frequency Analysis of North-Bank of the River Brahmuptra by Using LH-Moments. Water Resources Management

[9]. Lim ${ }^{1}$, Y.H.(2007) Regional Flood Frequency Analysis of the Red River Basin Using L-moments Approach.World Environmental and Water Congress2007: Restoring Our Natural Habitat.

[10]. National Institute Of Hydrology,(2000-2001) Water Balance Study Of Krishnai River Basin According To Thornthwaite's Concept Of Potential Evapotranspiration (CS/AR-2/2000-2001).Guwahati,India:Kumar Sh. S.R. 